\title{
Holistic approach to flood risk assessment in areas with cultural heritage: a practical application in Ayutthaya, Thailand
}

\author{
Zoran Vojinovic $^{1,2,3}$ - Michael Hammond ${ }^{1}$ - Daria Golub ${ }^{1}$. \\ Sianee Hirunsalee $^{4} \cdot$ Sutat Weesakul $^{5} \cdot$ Vorawit Meesuk $^{1}$. \\ Neiler Medina ${ }^{1}$ - Arlex Sanchez ${ }^{1} \cdot$ Sisira Kumara ${ }^{6}$. \\ Michael Abbott ${ }^{7}$
}

Received: 9 December 2014/ Accepted: 18 November 2015/Published online: 7 December 2015

(C) The Author(s) 2015. This article is published with open access at Springerlink.com

\begin{abstract}
This research proposes a holistic approach to flood risk assessment that combines quantitative and qualitative aspects. This approach was developed and applied in the Ayutthaya region in Thailand, which is a UNESCO World Heritage Site. First, flood risk was assessed traditionally as a product of hazard and vulnerability. Both qualitative and quantitative data were gathered from publicly available sources and through interviews, questionnaires, and focus group discussions to assess the vulnerability, using various weights for the different vulnerability dimensions. The hazard was assessed using a coupled 1D-2D flood model, and the resulting vulnerability and risk were mapped. Second, an alternative flood risk map was produced based on group mapping exercises with local residents, which captures the level of perceived risk. The traditional flood risk map was adjusted by varying the vulnerability weights to better match the perceived risk map. The analysis of these two maps revealed that two approaches to flood risk assessment can be used effectively in gaining different insights of the phenomena, and as such, they both should be used in flood risk management planning.
\end{abstract}

Keywords Flood risk - Flood management - Risk perception · Vulnerability - Cultural heritage $\cdot$ Holistic approach

Zoran Vojinovic

z.vojinovic@unesco-ihe.org

Michael Hammond

m.hammond@unesco-ihe.org

1 UNESCO-IHE Institute for Water Education, Delft, The Netherlands

2 University of Exeter, Exeter, UK

3 School of Civil Engineering, University of Belgrade, Belgrade, Serbia

4 Thammasat University, Rangsit Campus, Bangkok, Thailand

5 Asian Institute of Technology (AIT), Bangkok, Thailand

6 Asian Disaster Preparedness Center, Bangkok, Thailand

7 Knowledge Engineering BVBA, EIIL, Brussels, Belgium 


\section{Introduction}

Managing the risk of flooding is a significant challenge for many cities, and the magnitude of such challenge is expected to grow even further with an ever-continuing urbanisation, population growth, climate change, and economic growth (Huong and Pathirana 2013). Urban and economic growth results in more people, with more assets, living in concentrated areas, potentially exposed to flooding. Urbanisation and the development of impermeable areas also reduce the capacity for rainwater to infiltrate into the ground, leading to more run-off in less time (Kumar et al. 2013). Finally, climate change could bring more frequent extreme rainfall and increased extreme river flows (Arnbjerg-Nielsen et al. 2013; Pelling 2011). As a result, flood defence and urban drainage systems are often unable to cope with these added stresses (Price and Vojinovic 2008).

Flood risk can be defined as the likelihood of an extreme event combined with its negative consequences or impacts, calculated over a number of events with different probabilities. Expressed in a different way, risk can be defined as the combination of hazard and vulnerability (Apel et al. 2009; IPCC 2014; Vojinovic and Abbott 2012). We refer to this as the traditional (quantitative or analytical) approach to flood risk assessment. This approach relies upon the quantification of factors such as the value of exposed assets and the probability of extreme floods.

An alternative way of considering risk derives from a school of thought that suggests that the notion of risk is related to a pure or a priori conception of the understanding (Vojinovic and Abbott 2012) and the ability to sense and avoid harm (Slovic 1987). Although the results are conflicting, factors such as perceived probability and the perceived consequences of flooding have been shown to affect behaviour in some studies (Bubeck et al. 2012). We refer to this as the risk perception (qualitative or perceptive) approach to flood risk assessment, which uses more qualitative assessment techniques (Vojinovic and Abbott 2012).

Flood risk assessment (FRA) is a key tool in the traditional approach to understanding and managing flood risk. FRA can be used as a rational basis for decision-making and policy analysis (Hall et al. 2003). Flood risk assessed with this approach typically relies on the quantification of risk through computational flood modelling (see, for example, Vojinovic and Tutulic 2009), and the enumeration of assets at risk and their value. To obtain the most complete understanding of flood risk, all the dimensions of impacts or damage should be included (Merz et al. 2010). However, FRAs commonly focus on those impacts that can be quantified in financial terms, such as the cost of damage to property and business disruption. These readily quantifiable impacts do not reflect the entire effects of flooding, and those impacts that are difficult (or impossible) to express in non-monetary terms, such as the loss of life or the loss of cultural heritage, are often neglected (ten Veldhuis 2011). There is a limited yet growing literature into the vulnerability of cultural heritage to natural hazards and climate change (Colette 2007; Kincey et al. 2008; Marzeion and Levermann 2014). The use of maps has been shown to be a valuable tool in the risk assessment of cultural heritage (Wang 2015).

Vojinovic and Abbott (2012) argue that a holistic approach to flood risk management should be adopted, rather than a narrow techno-centric approach. Such a holistic approach should incorporate the views and perceptions of stakeholders, rather than merely the views of technical experts (Vojinovic 2014). We argue that a significant benefit of this perspective is the ability to combine the strengths of the two approaches to risk described above. Birkholz et al. (2014) argue that despite the growing awareness of holistic conceptions such as vulnerability, the role of risk perception is underdeveloped. As a result, 
there is a need to reinvigorate research into risk perception and its role in flood risk management.

The aim of this paper is to present a holistic approach to flood risk management by combining the traditional and risk perception approaches to an urban case study where invaluable sites of cultural heritage are threatened by floods. We argue that perceptions of flood hazard and flood risk provide a richer understanding of the problems and should be incorporated into strategies to manage flood risk. The development of such a holistic approach provides challenges. We discuss these challenges, and how they have been tackled; finally, we provide directions for how this research could be extended.

\section{Flood hazard and vulnerability assessment}

As described, flood risk is commonly defined as the product of hazard, (the physical and statistical characteristics of the floods) and the vulnerability of exposed environment (Wisner et al. 2004; Apel et al. 2009; Muller et al. 2011). The flood risk assessment process involves hydrological and hydraulic modelling to estimate the hazard, and socioeconomic studies to estimate the vulnerability to flooding (Cunha et al. 2011; Mynett and Vojinovic 2009). The following sections describe an overview of flood hazard and vulnerability assessment.

\subsection{Hazard assessment}

Urban flood hazard assessment typically relies upon the results from computational models. These models have progressed rapidly in recent years (Price and Vojinovic 2011; Abbott and Vojinovic 2009; Vojinovic et al. 2012; Seyoum et al. 2012). The simplest computational flood hazard models are based on hydrological models which represent the processes by which rainfall is converted into run-off. These models have progressed through one-dimensional models that represent flow in channels or subsurface sewers, to the state of the art, which is represented by coupled one-dimensional-two-dimensional hydraulic models. These models can simulate the behaviour of flow in sewers and channels, and on the surface around buildings (Henonin et al. 2013; Vojinovic et al. 2011). These models have significant data requirements; these include data on extreme rainfall, information on surface properties including permeability, roughness, and topography, and data on the layouts and geometry of channel networks including elevations, diameters, and the properties of any control structures. Flood hazard models are able to simulate the characteristics of flooding, which may include flooded extents, depths and velocities, flood durations, and water quality.

\subsection{Vulnerability assessment}

Vulnerability is commonly defined as referring to the conditions and capacities that make a system or an individual susceptible to harm as a result of a hazard (UNISDR 2009; Muller et al. 2011; Vojinovic and Abbott 2012). An understanding of flood vulnerability typically requires knowledge of the possible impacts of flooding. There is an extensive literature on flood damage or impact assessment (Messner et al. 2007; Merz et al. 2010; Hammond et al. 2015). Flooding has the potential to cause harm in many different ways, and these impacts can be considered as consisting of physical, social, institutional, economic, and 
environmental dimensions. Alternatively, the impacts can be divided into tangible (easily expressed in monetary terms) and intangible impacts on one hand, and direct (as a result with direct contact with floodwater) and indirect impacts on the other.

Vulnerability is often assessed using sets of site-specific indicators or measurements (Cutter et al. 2000; Birkmann 2007; Muller et al. 2011; Wilhelmi and Morss 2013; Vojinovic 2014). Multiple aspects can be combined using multicriteria methods (Meyer et al. 2009). For example, Kubal et al. (2009) implemented multicriteria vulnerability assessments in urban areas and investigated the physical, social, and ecological dimensions of vulnerability.

\subsection{Risk perception}

An alternative way of considering risk derives from a school of thought in that suggests that the notion of risk is related to one's ability to sense and avoid harm (Slovic 1987). Proponents of this approach argue that a number of factors affect the perception of risk. These factors include direct (and to a lesser extent indirect) experience of the hazard, perception of the probability and consequences of the realisation of the hazard, and the level of trust in science and public authorities (Slovic 1987; Wachinger et al. 2013). Additionally, social context and cultural cognition play a role in identifying the level of risk (Kahan 2012; Vojinovic and Abbott 2012). In order to analyse flood risk from the social perspective, it is necessary to exploit knowledge of those communities at risk (Kenyon 2007; Haase 2011; Peters-Guarin et al. 2012).

\subsection{Holistic approach}

As introduced earlier, the world is being overwhelmed by increasingly disastrous hydrometeorological events and these events cannot be considered in isolation. They are due to an ever-increasing extent directly attributable to various social, economic, historical, political, and even cultural causes. Therefore, we argue that for an in-depth understanding of the aspects that cannot be easily (or not at all) expressed in numerical and/or monetary terms and which are based on cultural values, opinions, judgements, feelings, and perceptions, a holistic approach which combines a range of quantitative and qualitative data and methods should be adopted. The next section describes a case study where such an approach has been developed and applied.

\section{Approach}

Here we describe a holistic approach to flood risk assessment, which integrates physical, economic, social, and cultural vulnerabilities, along with perceived risk. This approach relies on the combination of two separate approaches. The first is a multicriteria flood risk assessment which quantifies flood risk in terms of the city's physical, social, economic, and cultural vulnerabilities. The environmental dimension of vulnerability was neglected, since Ayutthaya represents an urban area without developed ecosystems or significant natural resources. The second approach rests on stakeholder participation to ascertain the perception of risk by local residents. These two approaches provide two alternative flood risk maps (i.e. quantitative and qualitative). The schematisation of the two approaches and their main components are shown in Fig. 1. Consequently, the two different but complementary 
approaches for flood risk assessment provide insights into the characteristics of a disaster that have different underlying factors.

Ayutthaya City in Thailand was chosen as the study site. Ayutthaya Island is located approximately $70 \mathrm{~km}$ north of Bangkok and has an area of $7.2 \mathrm{~km}^{2}$. The population of the island is over 40,000. The island is located at the confluence of three rivers: the Chao Phraya River, the Lopburi River, and the Pa Sak River; 289 ha are protected by the World Heritage Convection (Fig. 2). The Historic City of Ayutthaya covers $40 \%$ of the island and was inscribed on UNESCO's World Heritage List.

The area is susceptible to fluvial flooding generated in the upstream catchment, as well as pluvial flooding that can result from intense rainfall. The city recently experienced a devastating flood in 2011 when the entire island was inundated for over 4 weeks, and water depths exceeded $4 \mathrm{~m}$ in some locations.

The concept of community is central to the approach adopted in this study to assess flood risk holistically. The term "community" has many different meanings and interpretations, and communities can be defined in terms of geography, social class, gender, religious belief, and so on. In this study, geography is the determining factor. Through consultation with the Director of the Department of Public works, 33 unique communities were identified. These communities are formal voluntary organisations created by the residents of the island mainly for the purpose of cooperating with the local government to receive support or assistance. Households with higher incomes might not participate in community organisations since they do not require such external support, and so this bias is recognised.

\begin{tabular}{|c|c|c|c|}
\hline \multirow[b]{2}{*}{$\begin{array}{r}\text { DEFINITION OF } \\
\text { RISK }\end{array}$} & \multicolumn{2}{|c|}{ TRADITIONALAPPROACH } & \multirow{2}{*}{$\begin{array}{l}\text { RISK PERCEPTION APPROACH } \\
\text { Risk as a potential harm to a } \\
\text { person's life and what this } \\
\text { person values }\end{array}$} \\
\hline & Risk = Hazard & Vulnerability & \\
\hline $\begin{array}{r}\text { FACTORS } \\
\text { UNDERLYING } \\
\text { LEVEL OF RISK }\end{array}$ & $\begin{array}{l}\text { Hydrometeorological conditions } \\
\text { Catchment land use }\end{array}$ & $\begin{array}{l}\text { Land use of exposed areas } \\
\text { Demographics } \\
\text { Social and political institutions } \\
\text { Governance }\end{array}$ & $\begin{array}{l}\text { Level of knowledge } \\
\text { Beliefs and values } \\
\text { Media } \\
\text { Trust in experts } \\
\text { Cultural institutions } \\
\text { Past experience }\end{array}$ \\
\hline $\begin{array}{r}\text { DISASTER } \\
\text { CHARACTERISTIC }\end{array}$ & $\begin{array}{l}\text { Flood magnitude } \\
\text { Flood frequency } \\
\text { Uncertainties }\end{array}$ & $\begin{array}{l}\text { Direct/indirect damages } \\
\text { Tangible/intangible damages }\end{array}$ & $\begin{array}{l}\text { Familiarity } \\
\text { Controllability } \\
\text { Voluntariness of exposure } \\
\text { Catastrophic potential } \\
\text { Risk source }\end{array}$ \\
\hline $\begin{array}{l}\text { ASSESSMENT } \\
\text { TECHNIQUES }\end{array}$ & $\begin{array}{l}\text { Hydrological modelling } \\
\text { Hydraulic modelling }\end{array}$ & $\begin{array}{l}\text { Depth-damage curves } \\
\text { Expected annual damage } \\
\text { Vulnerability indices }\end{array}$ & $\begin{array}{l}\text { Heuristics } \\
\text { Cognition } \\
\text { Intuition }\end{array}$ \\
\hline OUTPUT & Hazardmap & Vulnerability map & $\begin{array}{l}\text { Risk perception } \\
\text { Risk acceptance } \\
\text { Risk behaviour }\end{array}$ \\
\hline
\end{tabular}

Fig. 1 Comparison of the two approaches to flood risk assessment (traditional or quantitative, and risk perception or qualitative, approach) 


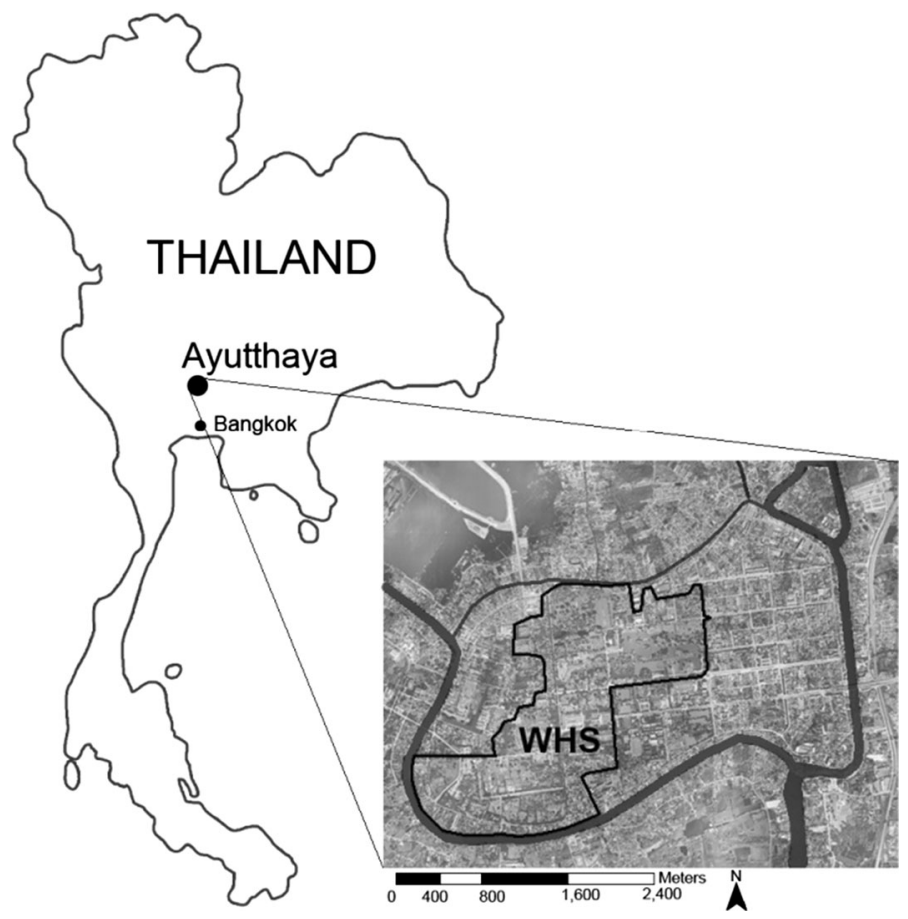

Fig. 2 Ayutthaya Island is located in Thailand and represents an urban area. Approximately one-third of the island is protected by UNESCO as a World Heritage Site (WHS)

\subsection{Overview of data collection methods}

Data for all the analyses were collected during 3 months of field work. An overview of these methods is given here. More specific details on how these were used to assess flood risk are provided in subsequent subsections.

\subsubsection{Initial meetings with project partners}

A series of meetings were held throughout the study to allow the collection of general background data. These included meetings with UNESCO Bangkok, the Asian Disaster Preparedness Center, the Ministry of Culture's Fine Arts Department, the Department of Public Works, and staff from the Municipality. These meetings were face to face and generated several outputs. For example, the Fine Arts Department was used to identify buildings of cultural heritage and both their significance and susceptibility (see Sect. 3.2.2.4).

\subsubsection{Two community workshops}

Two one-day workshops were held in order to collect data from the 33 identified communities, using focus group discussions and individual questionnaires. The first workshop was held on 29 April 2014 with over 300 representatives from 20 communities. The second workshop was held on 22 May and representatives of the remaining 13 communities were 
invited. In this instance, there were 32 participants from ten communities. Invitation letters had been sent door to door to the communities, inviting 3-5 members of each community, to include a community leader, a young man, a young woman, an elderly member, and a child under the age of 18 .

Each workshop used a focus group discussion approach, where each community was asked to identify critical community facilities (see Sect. 3.2.2.1), to complete a questionnaire to ascertain social vulnerability (see Sect. 3.2.2.2), and to provide information on perceived risk (see Sect. 3.3). The focus group discussions were conducted in the Thai language, and the responses were translated into English. These focus group discussion sessions were undertaken by a team of student volunteer researchers directed by a professional researcher. Finally, individual questionnaires were given to 150 participants in Thai to complete to provide information on the weighting of different categories of social vulnerability as well as other aspects of flood risk (not described in this article).

\subsubsection{Field survey work}

The same team of semi-professional student researchers led by a professional researcher conducted a door-to-door survey of the businesses that exist on the island, and categorised them into 20 classes. Twenty businesses, one from each category, were selected for an indepth semi-structured interview, which was conducted to estimate economic vulnerability to flooding (see Sect. 3.2.2.3).

\subsubsection{Four-day stakeholder consultation workshop}

A four-day stakeholder workshop was held from 27 to 30 May 2014 inclusive. Invitations were sent to 16 government and non-government organisations and representatives of the communities. Representatives from only eight organisations and five communities attended the workshop. However, this can be partly explained by the enactment of Martial Law in Thailand on 20 May which depressed attendance. This 4-day consultation workshop was part of a larger project and covered a number of topics, such as the selection of possible mitigation options, not reported in this article. One output of the stakeholder consultation was the identification of weightings for four dimensions of vulnerability (see Sect. 3.2.2.5).

\subsection{Traditional approach to flood risk assessment}

\subsubsection{Hazard analysis}

The hazard component of the risk equation is determined from a simulation of the 2011 flood event using combined 1D and 2D computational models. The focus of this paper is on the methodology for combining the risk models, and so the description of the hazard modelling is summarised. A 1D model of a 52-km stretch of the Chao Phraya River is developed, which consists of the channel data for the Chao Phraya River and a number of tributaries that include the Lopburi and Pasak Rivers which meet at Ayutthaya. Rainfall data from four raingauges and observed river stages are used as initial conditions. Second, a shorter section of this $1 \mathrm{D}$ model is coupled with a $2 \mathrm{D}$ model of the urban area, to investigate the propagation of excess floodwater from the 1D river system of the Pasak, Lopburi, and Chao Phraya Rivers into the urban area, using the DHI MIKE FLOOD 
software. Calibration was undertaken by means of adjusting Manning's $n$ roughness of the river channels and surfaces.

The 2D component of the model consisted of the topographic data of the island and its immediate surrounding area. Figure 3 shows the digital elevation model (DEM) of Ayutthaya Island. Aerial LiDAR data at a 2-m grid scale is used to generate the DEM of the island, which was used as the topography data for the $2 \mathrm{D}$ flood modelling.

Hazard is defined on the depth of inundation. Floodwater velocities are known to be low and can be neglected. A body of research is available about the relationship between flood characteristics and flood hazard (Penning-Rowsell et al. 2005; Jonkman et al. 2008; PetersGuarin et al. 2012). In this research, threshold depths of $<0.5,0.5-1.5$, and $>1.5 \mathrm{~m}$ were used to define the flood hazard as low, medium, and high, respectively.

\subsubsection{Vulnerability assessment}

Four dimensions of vulnerability are differentiated to represent flood effects on different aspects of the urban environment: physical, social, economic, and cultural dimensions. The vulnerability assessment relied on data collected from GIS maps with information on buildings and land use types, interviews with key stakeholders, and focus group discussions. Each dimension was assessed in isolation and combined into a single vulnerability map using multicriteria techniques.

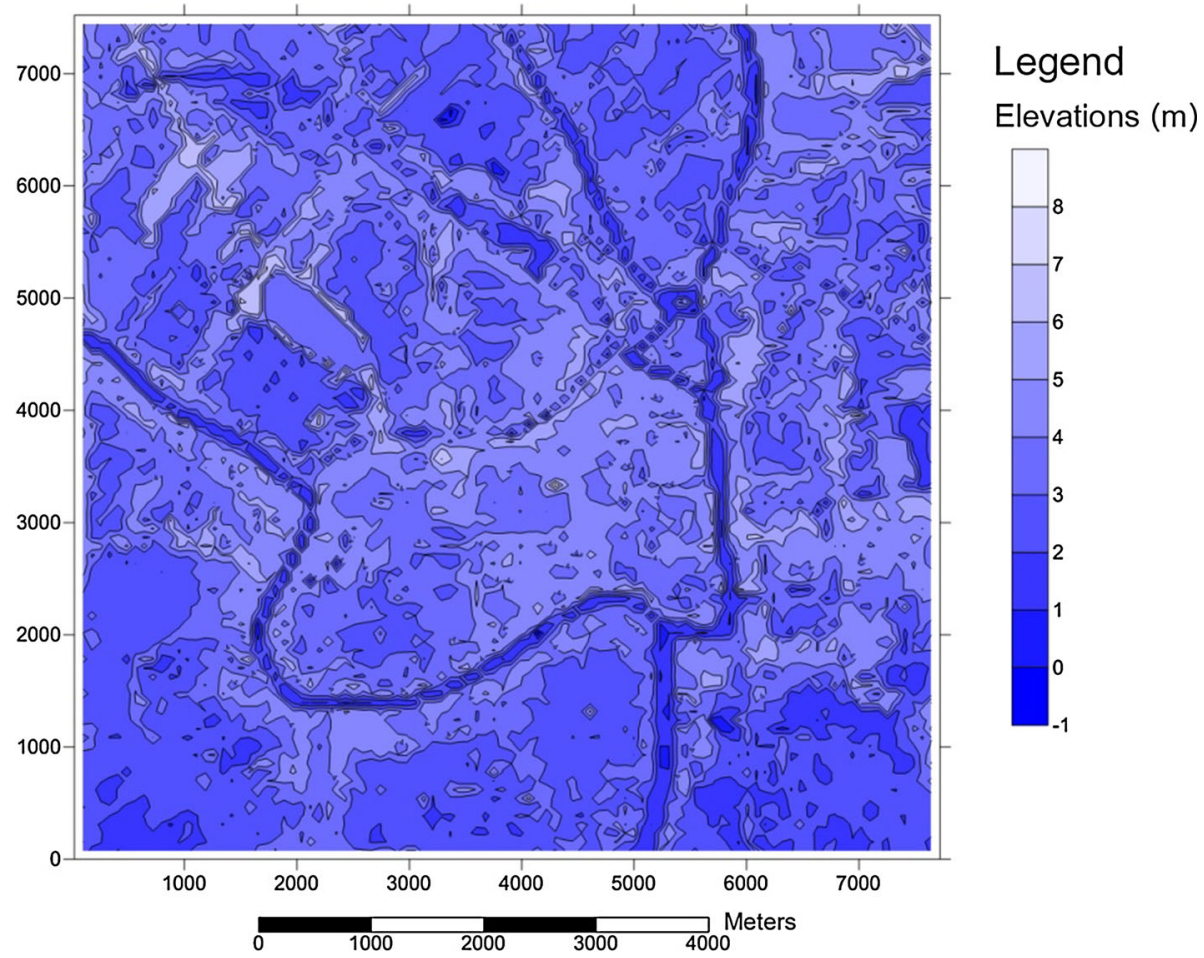

Fig. 3 Contour topography of Ayutthaya Island derived from 2-m grid scale resolution data 
3.2.2.1 Physical vulnerability To assess physical vulnerability, four different classes of the built environment are identified: residential buildings, cultural properties, critical infrastructure, and roads. Within each group, individual asset types are categorised as exhibiting low, medium, or high vulnerabilities (Fig. 4).

Research conducted after the 2011 flood demonstrated that the damages associated with three types of residential building varied significantly (Mongkonkerd et al. 2012). Singlestorey buildings are the most vulnerable, since there is no flood-free storey. In two-storey houses, valuable assets, such as furniture and household appliances, can be temporarily moved upstairs reducing the overall damage. Pillar houses are the least vulnerable, since these houses are elevated and are rarely affected by floodwater (Fig. 5).

The cultural properties are divided into three classes following advice from experts from the Ministry of Culture's Fine Arts Department. Restored or reinforced properties are assigned low level of vulnerability since new materials can withstand flood waters. Archaeological properties with only a few remains are assigned a medium level of vulnerability, since such structures can be affected by mechanical and chemical erosion due to flooding, but structural collapse is unlikely. The most vulnerable cultural properties are non-restored properties where structural collapse may occur due to destabilised foundations or soil subsidence caused by flooding, as well as due to prolonged saturation of weight-bearing elements.

Critical facilities are identified from group mapping exercises involving local residents and the key stakeholders. Participants are asked to identify the following critical infrastructures: hospitals, schools, the university (used as potential evacuation centres), and some active temples. All critical facilities are considered to be highly vulnerable. Furthermore, roads are classified into three types: asphalt road (low vulnerability), gravel roads (medium vulnerability), and unpaved roads (high vulnerability).

3.2.2.2 Social vulnerability The community was chosen as the appropriate scale for assessing social vulnerability, and it is assessed using a framework published by Turner et al. (2003), which consists of analysing the exposure, susceptibility, and capacities of each community. Exposure captures the extent to which social subsystems might be affected by flooding, and it can be measured by the percentage of households that could potentially be flooded (Damm 2010). Susceptibility aims to describe the state of communities and to determine their rate of deterioration (Damm 2010; Turner et al. 2003). Capacity, or capacities, represents the strengths and resources available in the communities (Damm 2010). Coping and adaptive capacity can be identified as subcomponents of these capacities. Coping capacity is the way people and organisations use available resources and abilities to face adverse consequences (UN/ISDR 2004). Adaptive capacity reflects the learning aspects of system behaviour in response to floods (Gunderson 2000).

BUILT ENVIRONMENT

\begin{tabular}{|c|c|c|c|c|}
$\begin{array}{c}\text { VULNERABILITY } \\
\text { CLASS }\end{array}$ & Residential buildings & Cultural properties & Critical infrastructure & Roads \\
\hline Low & Pillar house & Restored & Asphalt roads \\
\hline Medium & Two-storey house & Archeological remains & $\begin{array}{c}\text { Hospitals, police } \\
\text { stations, water supply, } \\
\text { ATM }\end{array}$ & Gravel roads \\
\hline High & One-storey house & Not restored & \begin{aligned} Unpaved roads \\
\hline\end{aligned} \\
\hline
\end{tabular}

Fig. 4 Categorisation of build environment into three vulnerability classes 


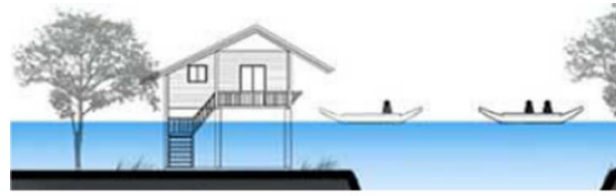

(a)

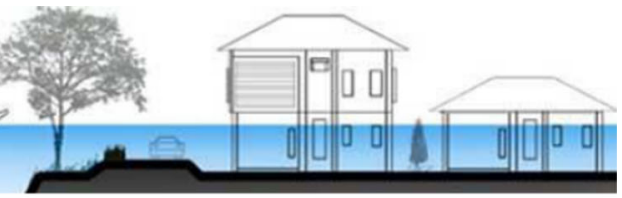

(b) (c)

Fig. 5 Three types of residential buildings differentiated for physical vulnerability assessment on Ayutthaya Island: a pillar house, b two-storey building, and c single-storey building (after Mongkonkerd et al. 2012)

Precautionary measures such as spatial planning, land use management, and financial resources are examples of factors affecting adaptive capacity (Damm 2010).

A methodology was applied that identified indicators that can measure the qualities of the community of interest and their relationship with vulnerability. Eight indicators of social vulnerability were identified, and these are listed in Table 1. Four of these indicators relate to susceptibility and four to capacities. There is naturally some vagueness in determining these capacities as susceptibility might derive from a lack of capacity. A questionnaire was developed with 42 questions grouped into these eight indicators. These questions either used a binary (yes/no) scale or on a three-point scale (majority/all, approximately even, minority/none). These scores were translated into either 0 or 1 for the binary scale, or $0,0.5$, or 1 for the three-point scale. The arithmetic mean was calculated for the questions under each category, for each community.

Trained facilitators completed the questionnaire on behalf of the community representatives. FGDs have been widely used to study vulnerability at the community level in other case studies (ADPC 2009). In such an environment, it is possible that the focus groups are influenced by the facilitator, or by dominant members of the group. The facilitators had undergone basic training and were aware of these possible effects, and their removal cannot be guaranteed.

To obtain a composite score for community social vulnerability workshop, participants were individually asked to rank the importance of the four susceptibility and four capacity parameters. These results are used to weight the indicators, with the susceptibility and capacity parameters split 50:50.

3.2.2.3 Economic vulnerability The economic dimension of vulnerability was assessed by analysing the response of businesses to flooding during the event and afterwards, in the recovery period. Business continuity management theory was used to assess economic vulnerability. Here, a business is considered resilient to flooding if it implements a business

Table 1 Categories and indicators for the assessment of the social dimension of vulnerability at a community level

\begin{tabular}{ll}
\hline Category & Indicators \\
\hline Susceptibility & 1. Health risks caused by floods \\
& 2. Vulnerable groups \\
3. Flood effect on income/livelihood & 4. Flood effect on property \\
Capacities & 5. Flood awareness \\
& 6. Flood preparedness \\
7. External support & 8. Community cohesiveness \\
\hline
\end{tabular}


continuity plan (PACE 1998). The vulnerability of a given economic activity was assessed by considering the following parameters:

- Duration of complete shutdown of the business due to a flood event;

- Duration of reduced business activity caused by a flood event; and

- Operational capacity during reduced activity.

The area of the island was divided into eight areas, and a team of 24 students conducted a door-to-door survey to identify the different businesses which were categorised into 20 groups. One business owner from each of these groups was selected to be the subject of an in-depth interview. Twenty semi-structured interviews were completed with representatives of business owners in order to evaluate a set of parameters for economic vulnerability. Interviewees were asked to answer questions based on their experience from the 2011 flood event. The economic vulnerability score was calculated using the following equation:

$$
\mathrm{VS}=I \times T_{\mathrm{sd}}+I \times T_{\mathrm{d}} \times C_{\mathrm{d}},
$$

where VS denotes vulnerability score, $I$ denotes income level before the 2011 flood event, $T_{\text {sd }}$ denotes the duration of complete shutdown (months), $T_{\mathrm{d}}$ denotes the duration of reduced activity (months), and $C_{\mathrm{d}}$ denotes operational capacity during downsizing phase (portion in comparison with normality). The results of this analysis will permit a classification of appropriate thresholds for low, medium, and high vulnerabilities.

3.2.2.4 Cultural vulnerability The cultural dimension of vulnerability captures the effect of flooding on cultural values embodied in various properties. These values include the historical, spiritual, aesthetic, and social values that constitute the cultural significance of a property (Daly 2011; Vecvagars 2006). These can be associated with different property attributes, such as its location and setting, materials, form, and shape (UNESCO World Heritage Centre 2012). The level of cultural vulnerability was assessed by considering the significance and sensitivity of the cultural assets in areas exposed to flooding.

The significance of each property was assessed on a scale of $1-5$, where 1 indicates that a property is not culturally significant and 5 represents very high cultural significance. Properties were ranked as very high cultural significance (5) if they lie within the World Heritage Site. At the community workshops, individuals were asked which properties from a list were significant. The number of responses will be used to assign low, medium, and high cultural significance. Those not mentioned will be assigned very low significance.

The sensitivity of each property was assessed on a scale of $1-4$, where 1 indicates low sensitivity to floodwaters and 4 represents high sensitivity. For instance, low sensitivity could be assigned to properties whose cultural significance would not be diminished by changes to its physical structure, such as those sites granted significance by virtue of their location alone. In contrast, archaeological remains that are considered significant because of the nature of the materials used in the structure, and where those materials could be damaged or compromised by floodwaters, were assessed as being highly sensitive to flooding. The sensitivity for properties was assessed working with experts at the Fine Arts Department.

The overall vulnerability of a cultural property was assessed by combining the results from the sensitivity and significance, using the matrix shown in Table 2.

3.2.2.5 Combined vulnerability assessment Each of the four dimensions of vulnerability is given a value of 1,2 , or 3 , depending on whether their vulnerability is classified as low, 
Table 2 Matrix to define a level of vulnerability for cultural properties

\begin{tabular}{lllll}
\hline Level of property significance & \multicolumn{4}{l}{ Score of property sensitivity } \\
\cline { 2 - 5 } & Low & Medium & Medium-high & High \\
\hline Very low & Low & Low & Low & Medium \\
Low & Low & Low & Medium & Medium \\
Medium & Low & Medium & Medium & High \\
High & Medium & Medium & High & High \\
Very high & Medium & High & High & High \\
\hline
\end{tabular}

medium, or high. At the consultation workshop, a questionnaire was distributed to each stakeholder organisation or community to estimate a percentage weight of each dimension of vulnerability. The arithmetic mean of all returned questionnaires would be used to calculate the overall vulnerability weights. The resulting vulnerability score was then normalised between 0 and 1 . Because the buildings, assets, and communities assessed have different spatial extents and resolution, they were converted from vector formats to a raster format with a 1-m resolution.

\subsubsection{Combined risk assessment}

The combined risk assessment is made by multiplying the vulnerability (normalised between 0 and 1 ) and the hazard score (normalised as $0.33,0.66$ and 1) to produce a risk score from 0 to 1 . The three classes of low, medium, and high risk were calculated by using Jenks Natural Break Optimisation, a way of identifying classes and reducing variance within each class. Scores $<0.25$ were considered low risk, from 0.25 to 0.45 were considered medium risk, and greater than 0.45 were considered high risk.

\subsection{Risk perception approach to flood risk assessment}

During the community workshops, a group mapping exercise was used to assess the phenomena and perception of risk by communities threatened by flood hazards. Participants of the communities' workshop were organised into eight groups based on the location of their homes, Fig. 6. Each group consisted of 12-15 people representing four or five communities. The group work was conducted in the Thai language, and a native Thai speaker facilitated the workshop to ensure that communication was natural for participants.

The facilitator of the exercise first provided an introduction to the concept of risk. The introduction was based on the fact that as human beings we can naturally assess risk for our lives and for what we value (e.g. health, family, and possessions) in activities such as transport choices, the food we eat, and social activities. However, perceived risk may not equate with the risk calculated from statistics. It is well documented that people use a number of heuristics or mental shortcuts to estimate risks, and they can have particular biases. For example, people tend to estimate risks to be lower than in reality if they perceive the activity to be beneficial. If the hazard can be recalled through recent direct or indirect experience, people tend to overestimate the risk, known as the availability bias (Slovic and Peters 2006; Tversky and Kahneman 1974).

After the introduction, participants were invited to think about Ayutthaya Island as a human body and about the potential negative effects that flooding might cause. This is a 

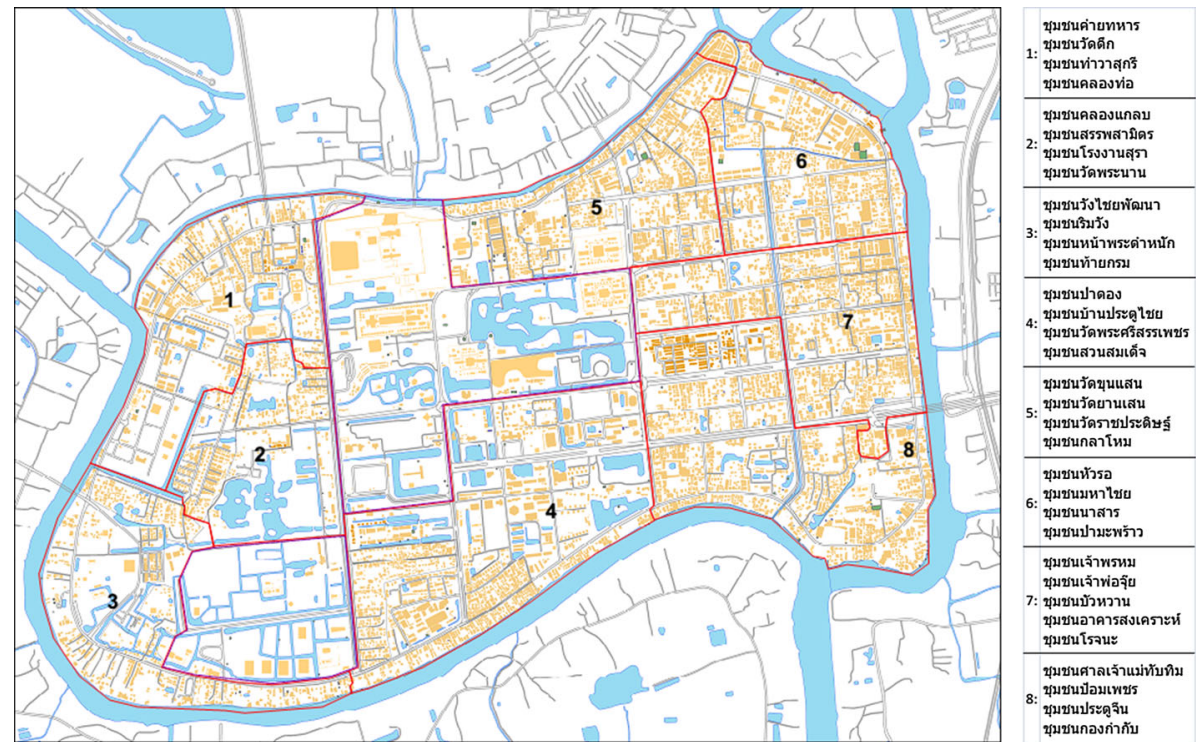

Fig. 6 Residential territory of the island was divided into eight sectors. Community representatives from each sectors formed a group to accomplish group mapping exercise

form of phenomenological research which aims to gather "deep" information and perceptions of the phenomena, representing it from the perspective of people who experienced it directly. Thus, people could think of the relative importance of different parts of the town, the level of exposure, the existing coping capacities, etc. Participants were then encouraged to share their feelings regarding flood risk in the area of their residence and to voice their thought processes. Afterwards, a group of 12-15 people worked together to create a map of perceived risk for a given area. Participants were encouraged to express an agreed level of risk by colouring in a blank map provided to them. Three different colours were used to indicate areas of low, medium, or high perceived risk. It was noticed that group mapping exercises created a playful and interactive environment, making them an attractive exercise for participants, which increases its suitability for the investigation of risk perception.

It is important to stress that residents were introduced to risk using a social definition of risk as the potential harm to a person's life and to what this person values. As a result, the results of group mapping exercise represent the combined assessment of risk, not only hazard. It would have been interesting to have investigated how the group dynamics affected the perception of risk, in comparison with perceptions residents might have prior to the workshop.

\subsection{Holistic approach to flood risk assessment-combining the two maps}

Two alternative maps of the flood risk will have been produced from the two methods. The first map will combine information from flood models and hazard maps, along with field survey data and questionnaires to assess the vulnerability (i.e. quantitative or analytical approach). The second map will rely on the perception of risk from local residents (i.e. qualitative or perceptive approach). To assess flood risk holistically, it is necessary to go 
beyond merely producing these alternative maps, but to gain a richer understanding of flood risk by transcending the information provided in these two maps. We aim to achieve this in two ways: first by identifying the similarities and differences between the two maps and second by adjusting the weights attached to the vulnerability dimensions in the traditional flood risk map to achieve a closer match with the perceived risk map. The purpose is not to do a rigorous calibration of the traditional flood risk map against the risk perception map, but rather to use the information from one to learn about another. We argue this is possible because the perceived risk from the 2011 event is likely to be representative of the true risk because it was so fresh in the mind of the respondents. This process is necessarily explorative in its methodology.

A difficulty arises in comparing the two maps because of their spatial data format. The traditional flood risk map uses 1-m raster grid cells, while the risk perception map is based upon polygons of varying sizes. To enable comparison between the two maps, the raster representation is converted to a polygon representation. Each raster cell in the traditional flood risk assessment has a score between 0 and 1 . The arithmetic mean of these raster values is calculated over each polygon (excluding cells without a numerical value). The areas where residents did not comment on the risk are excluded from this conversion.

An alternative way of converting the raster representation of flood risk to the polygon representation will be assessed. A polygon in the traditional flood risk map will be classified as being in a state of high risk if a certain fraction of the raster cells within the polygon is calculated as high risk. Four methods are tested

a. Designating a polygon as high risk if $10 \%$ of the raster cells are high risk. If the $10 \%$ threshold is not exceeded, calculate the mean value of cells over the polygon.

b. Designating a polygon as high risk if $10 \%$ of the raster cells are high risk. If the $10 \%$ threshold is not exceeded, calculate the modal value of cells over the polygon.

c. Designating a polygon as high risk if $6 \%$ of the raster cells are high risk. If the $10 \%$ threshold is not exceeded, calculate the mean value of cells over the polygon.

d. Designating a polygon as high risk if $13 \%$ of the raster cells are high risk. If the $10 \%$ threshold is not exceeded, calculate the mean value of cells over the polygon.

Once the most effective method of converting the raster to the polygon format is selected, the weights of the four vulnerability classes were systemically varied so as to see whether the agreement between the two maps can be improved. Thirty runs are conducted which are grouped as follows.

a. Equal weight to all classes (Scenario 1)

b. One class removed completely, and remaining three given equal weight (Scenarios 2-5)

c. One class given $50 \%$ weighting, and remaining three given equal weight from remaining share (Scenarios 6-9)

d. Two classes given weights of $40 \%$ each, and two classes given weight of $20 \%$ each (Scenarios 10-15)

e. Two classes removed completely, and remaining two given equal weight (Scenarios 16-21)

f. Three classes given $30 \%$ weight each, and one given $10 \%$ (Scenarios 22-25)

g. One class given $70 \%$ weight, and remaining classes given $10 \%$ each (Scenarios 26-29)

h. The weighting from the original survey results selected as untrustworthy (Scenarios 30) 
Visual inspection and a simple metric are adopted to assess the agreement between the two maps. Agreement is quantified as the number of polygons with the same risk classification (low, medium, or high) as a proportion of the total number of polygons.

\section{Results}

\subsection{Traditional approach to flood risk assessment}

The first part of the traditional (or quantitative) approach to flood risk assessment is the calculation of flood hazard. This was estimated from the MIKE FLOOD model described earlier. The resulting hazard map is shown in Fig. 7, with areas denoted as low, medium, or high risk, using depth thresholds of $<0.5 \mathrm{~m}$, between 0.5 and $1.5 \mathrm{~m}$, and greater than $1.5 \mathrm{~m}$. Much of the island is inundated during the 2011 event to depths greater than $0.5 \mathrm{~m}$, signifying at least medium hazard. Much of the World Heritage Site, which lies on the west of the island, is inundated to depths greater than $1.5 \mathrm{~m}$, signifying high risk.

The second component of the traditional approach to flood risk assessment is the estimation of vulnerability. Each of the four dimensions of vulnerability is given a value of 1,2 , or 3 , depending on whether their vulnerability is low, medium, or high. The four dimensions of vulnerability were combined into a single score using the results of the stakeholder questionnaire presented at the stakeholder/consultation workshop as described earlier.

Physical vulnerability was mapped by selecting the maximum vulnerability within any 1-m raster cell. For example, if a 1-m cell contains both elements of a highly vulnerable critical facility, and part of a low vulnerability asphalt road, the highly vulnerable element dominates and that cell is marked as highly vulnerable.

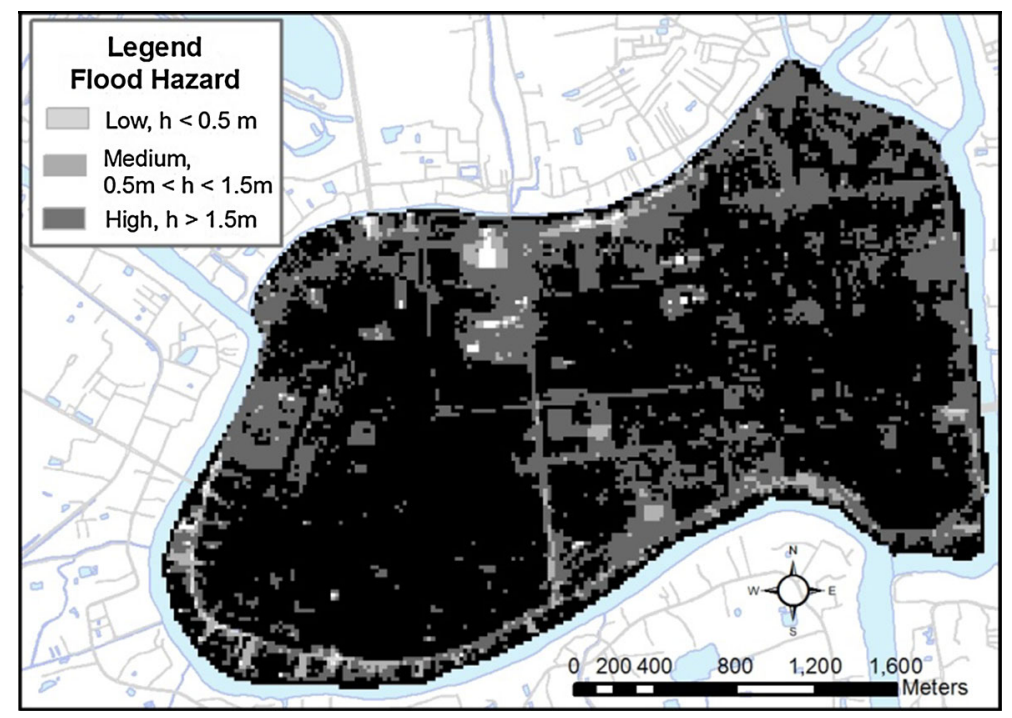

Fig. 7 Flood hazard map of the extreme flood event in 2011. The levels of hazard are identified based on threshold values of 0.5 , and $1.5 \mathrm{~m}$ depth of inundation 
Social vulnerability was calculated for 30 communities, by combining the scores from eight variables, using the weights shown in Table 3.

Economic vulnerability was assessed by identifying seven business sectors (non-tourist accommodation, non-tourist goods and foods, non-tourist transportation, tourist accommodation, tourist food and drink, tourist services, and tourist transportation). Based on threshold scores of $0-1.99,2-3.99$, and $4-6$, economic vulnerability was assessed as low, medium, or high. The results are shown in Table 4.

Cultural vulnerability was based on the results of 78 completed questionnaires and consultation with the Fine Arts Department. Outside of the World Heritage Site, the property considered the most significant was the Chantharakasem National Museum, selected by 59 respondents. Properties with more than 40 responses were considered highly significant. The threshold for low and medium were 1 and 20, respectively.

During the final consultation meeting, respondents were asked to weight the relative importance of the four different vulnerability dimensions, so as to create the combined vulnerability map. The results from this survey are shown in Table 5. However, political instability led to only eight respondents attending the workshop, and the results were considered unreliable. As a result, default values of equal weighting were applied. The polygons of various sizes were converted into a raster format using 1-m grids to allow aggregation.

The individual vulnerability maps for the physical, social, economic, and cultural vulnerabilities are shown in Figs. 8, 9, 10, and 11, and the combined map is shown in Fig. 12.

Following the procedure established in Sect. 4, the combined flood risk map is produced and is shown in Fig. 13.

\subsection{Risk perception approach to flood risk assessment}

Data gathered through group mapping exercises were converted into a GIS format, and a single risk perception map was created for Ayutthaya Island. The territory of the World Heritage Site is not covered, since the community members did not consider themselves to have the required knowledge, but rather commented that it was the responsibility of appropriate experts to judge the risk for that area. Communities' representatives said that they were not aware of heritage's vulnerability and condition, as well as the possible

Table 3 Set of eight parameters to assess social dimension of vulnerability at the community level
The percentage indicates the weight of each parameter into overall vulnerability score

\begin{tabular}{lc}
\hline Parameter & Parameter weight (\%) \\
\hline Capacity & 14 \\
Flood awareness & 16 \\
Flood preparedness & 9 \\
External support & 11 \\
Community cohesiveness and education & \\
Susceptibility & 14 \\
Health & 15 \\
Property & 12 \\
Income/livelihood & 9 \\
Vulnerable groups & 100 \\
Total & \\
\hline
\end{tabular}


Table 4 Scores of economic vulnerability for each type of business

\begin{tabular}{llllll}
\hline $\begin{array}{l}\text { Type of } \\
\text { businesses }\end{array}$ & $\begin{array}{l}\text { Shutdown } \\
\text { phase } \\
\text { (months) }\end{array}$ & $\begin{array}{l}\text { Reduced } \\
\text { business } \\
\text { activity } \\
\text { (months) }\end{array}$ & $\begin{array}{l}\text { Operational capacity } \\
\text { during reduced activity } \\
\text { (portion in comparison to } \\
\text { normality) }\end{array}$ & $\begin{array}{l}\text { Vulnerability } \\
\text { score }\end{array}$ & Vulnerability \\
\hline $\begin{array}{c}\text { Non-tourist: } \\
\text { accommodation }\end{array}$ & 1 & 2 & 0.9 & 2.8 & Medium \\
$\begin{array}{c}\text { Non-tourist: } \\
\text { goods stores } \\
\text { and food }\end{array}$ & 1 & 3.5 & 0.2 & 1.7 & Low \\
$\begin{array}{c}\text { Non-tourist: } \\
\text { transportation }\end{array}$ & 1.5 & 2.5 & 0.2 & 2.0 & Medium \\
$\begin{array}{c}\text { Tourist-oriented: } \\
\text { accommodation }\end{array}$ & 2.0 & 3.7 & 0.7 & 4.6 & High \\
$\begin{array}{c}\text { Tourist-oriented: } \\
\text { food and } \\
\text { beverage }\end{array}$ & 3.7 & 4.0 & 0.2 & 4.6 & High \\
$\begin{array}{c}\text { Tourist-oriented: } \\
\text { services }\end{array}$ & 2.0 & 1.5 & 0.4 & 2.6 & Medium \\
$\begin{array}{c}\text { Tourist-oriented: } \\
\text { transportation }\end{array}$ & 2.5 & 3.0 & 0.8 & 4.9 & High \\
\hline
\end{tabular}

Table 5 Weights of vulnerability dimensions from questionnaire and default value

\begin{tabular}{lll}
\hline Vulnerability dimension & Weight from questionnaire & Weights used in study \\
\hline Physical & 0.22 & 0.25 \\
Social & 0.19 & 0.25 \\
Economic & 0.21 & 0.25 \\
Cultural & 0.38 & 0.25 \\
\hline
\end{tabular}

effects of flooding on the properties. The resulting perceived flood risk map is shown in Fig. 14.

The map shows how elevated risk around the fringe of the island, with lower risk in the centre. In general, the central eastern part of the island is perceived by residents as having a low level of flood risk, where people mentioned that they are prepared for flooding and can withstand the disaster. It is suggested that this confidence is because the local residents witness flooding of the areas adjacent to the island almost annually and they see how people cope with a disaster. This experience may give the residents the sense that flooding is not a big disaster and can be coped with. However, analysis of social vulnerability revealed a lack of flood preparedness, and so this confidence may be misplaced. Interestingly, during the flood of 2011, residents in this area suffered significantly from flooding and had to evacuate and rely completely on external support, and were therefore not well prepared to a disaster. 


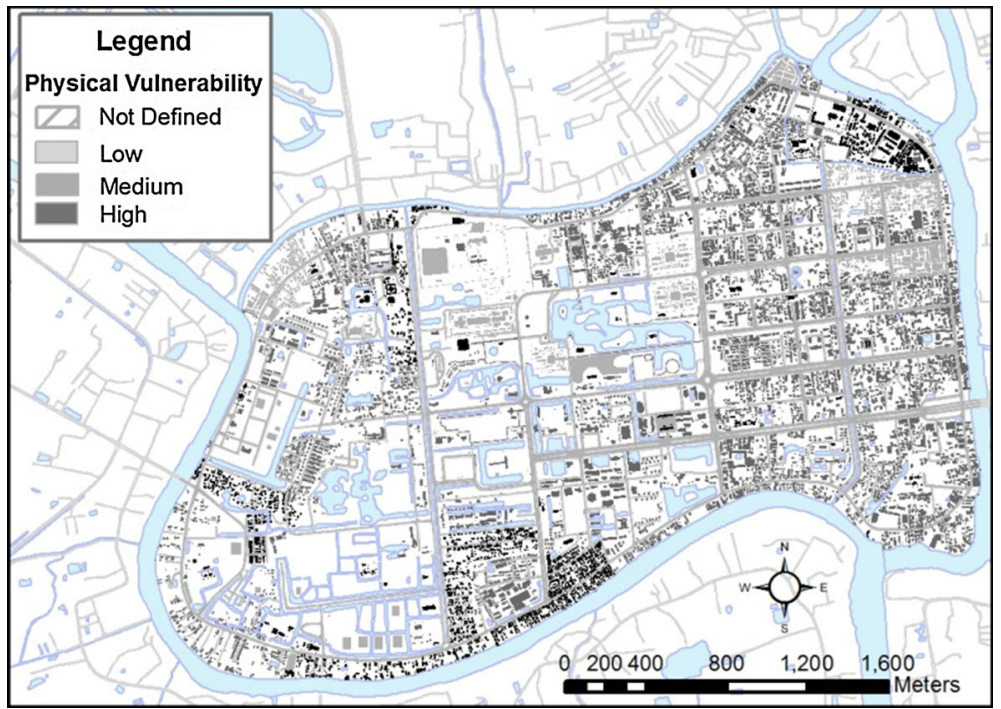

Fig. 8 Physical vulnerability

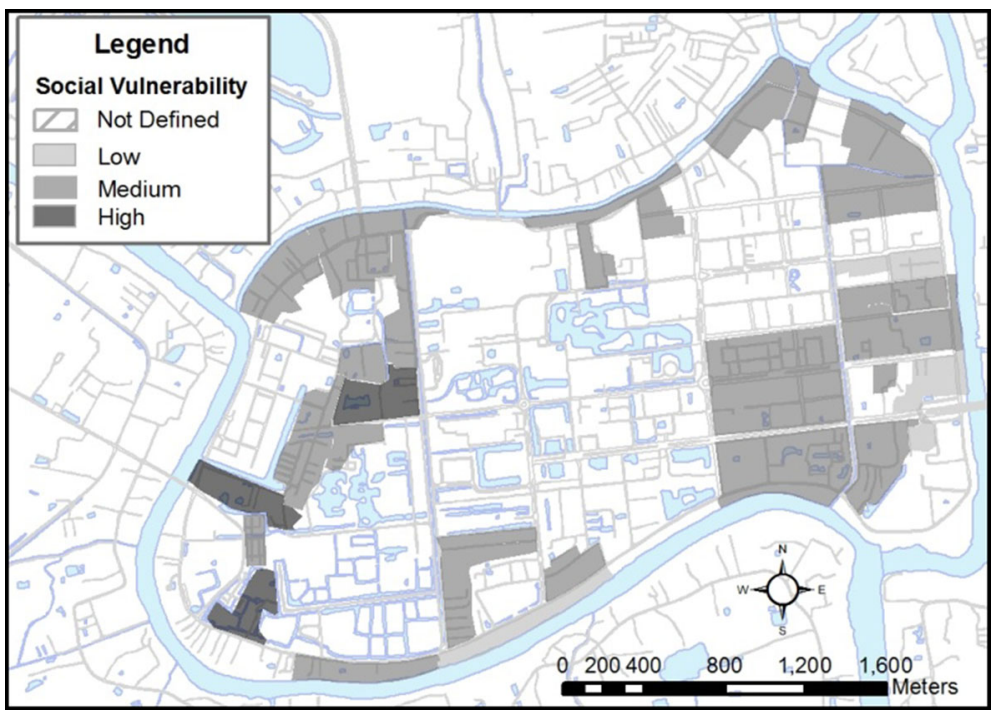

Fig. 9 Social vulnerability

\subsection{Holistic approach to flood risk assessment: combining the two maps}

Two different flood maps have been developed and are presented in Sects. 4.1 and 4.2. Figure 13 shows the flood map calculated quantitatively by combining hazard, exposure, and vulnerability information. Figure 14 shows the perceived flood risk. Visual inspection determines that there are a number of agreements and disagreements between these two 


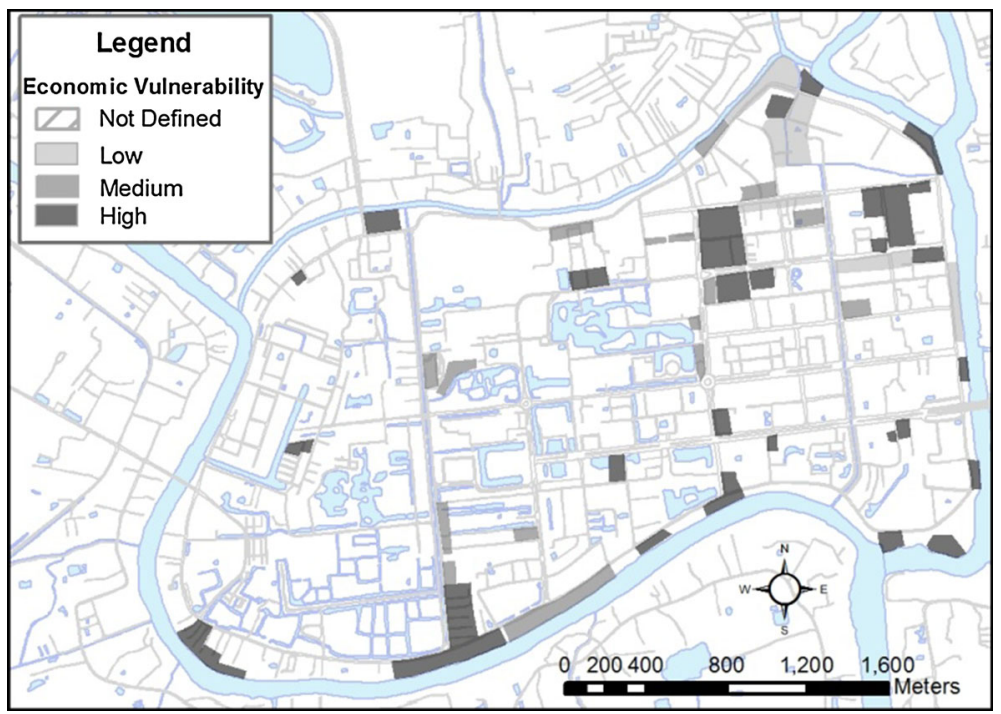

Fig. 10 Economic vulnerability

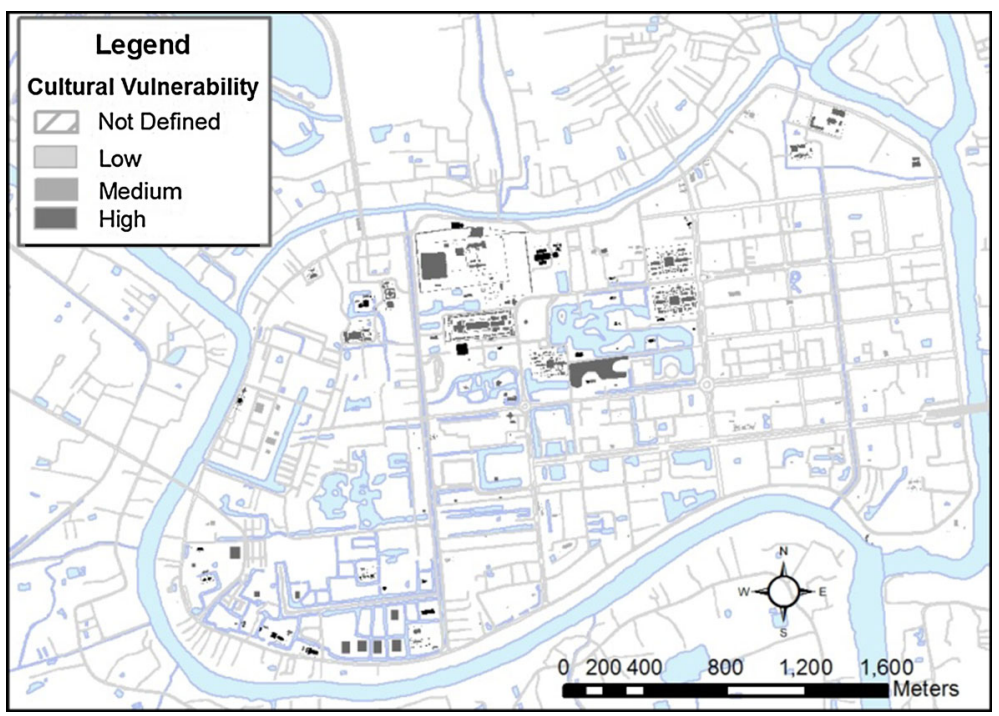

Fig. 11 Cultural vulnerability

maps. The flood risk is high in both maps in the southern edge of the island near the hospital areas. There is also agreement abut high flood risk in the east and north-east of the island. Lower risk in the central western area is observed in both maps. Along the north side of the island, there is general agreement on the level of risk. In the middle and west of the northern side of the island, the risk is perceived to be high. People mentioned very high flood depths during the 2011 flood event in this area. There are also several significant 


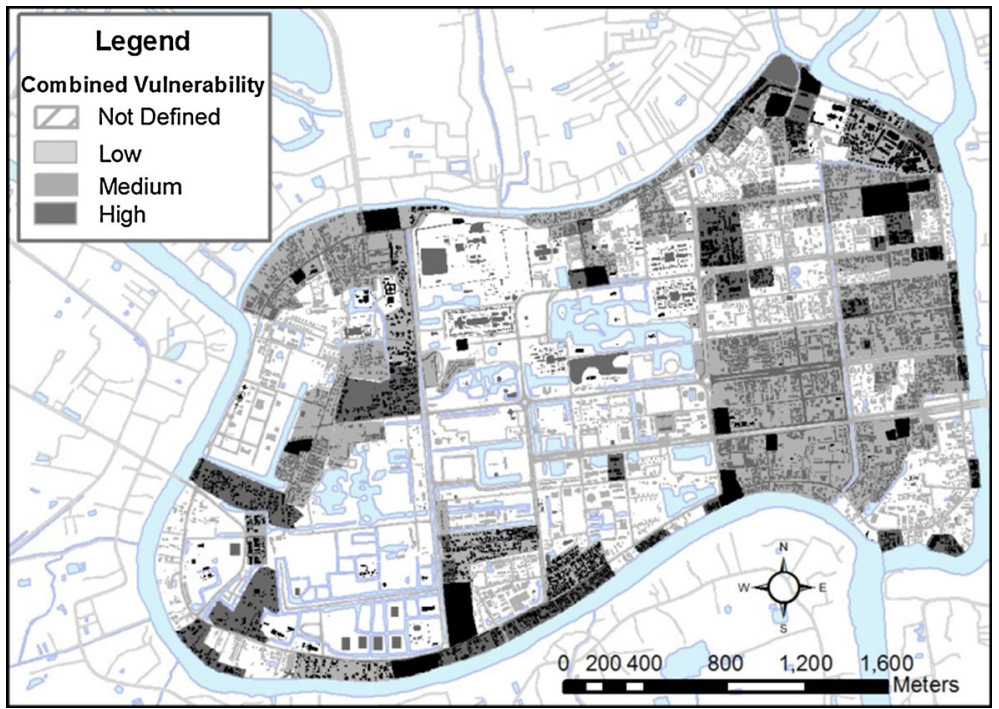

Fig. 12 Combined vulnerability

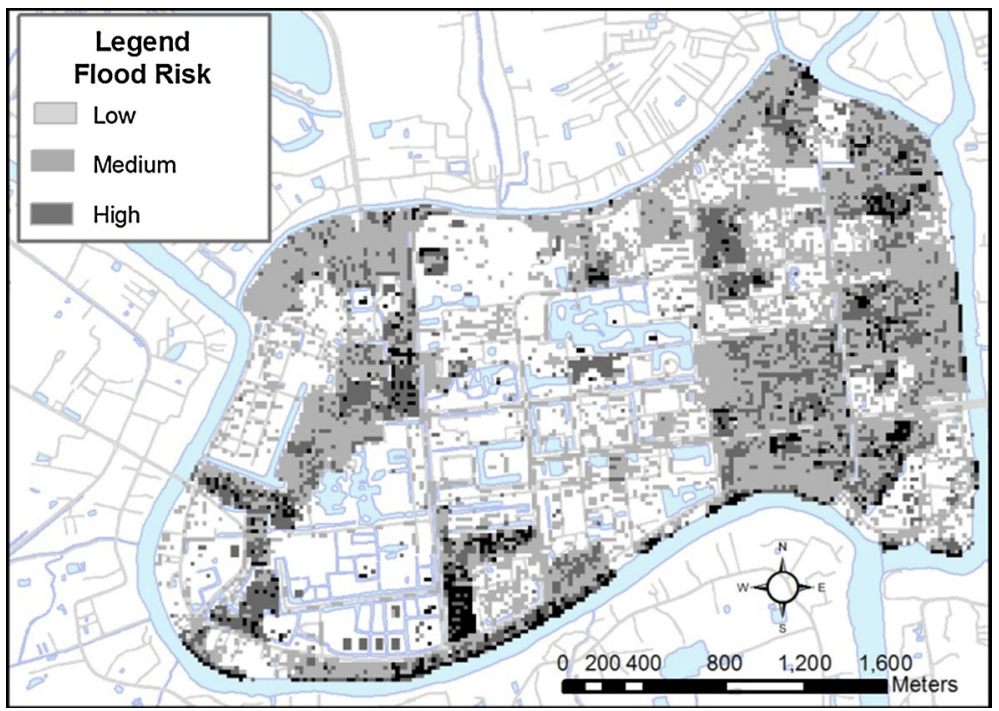

Fig. 13 Combined flood risk map by traditional approach

structures, which include the university (which serves as an evacuation centre), a temple, and a school. These buildings are reflected on the "traditional risk map" as isolated pixels with high or medium level of risk. In the north-eastern part of the island, both maps show significant areas of high and medium level of risk based which reflects the presence of high-density commercial area. However, some residents mentioned that commercial 


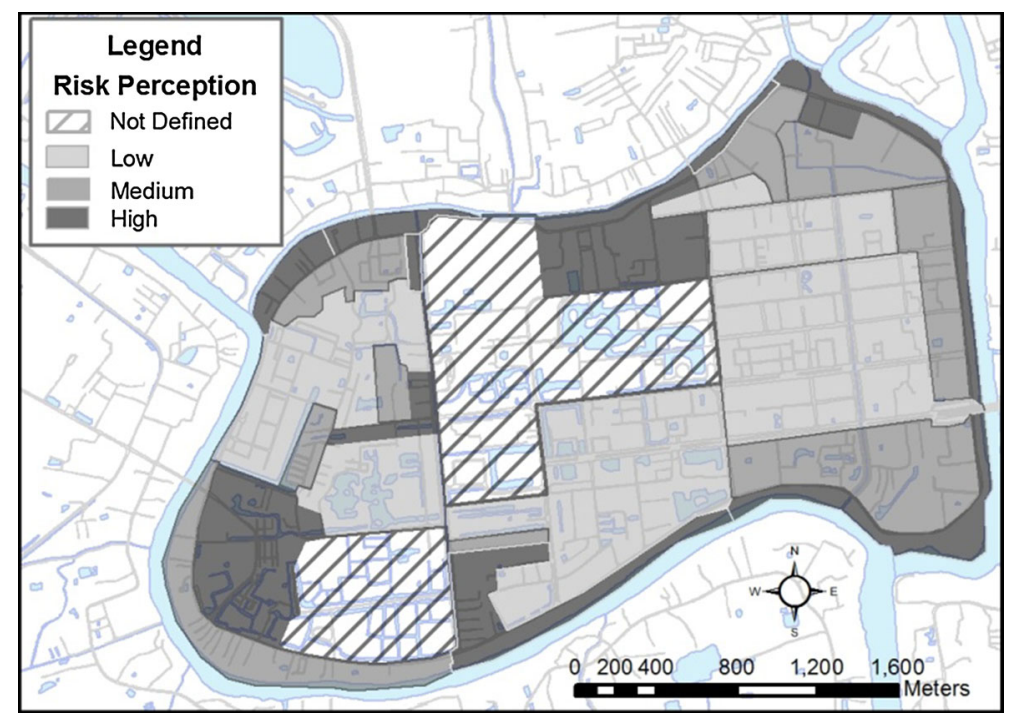

Fig. 14 Perceived flood risk map (qualitative or perceptive approach)

buildings mostly have at least two storeys, and therefore, people could move to the upper floors, thereby adapting to flooding.

In the south-west corner of the island, there is a noticeable disagreement between the risk which is perceived to be high by the local residents, and the generally low or medium risk calculated by the traditional approach. Even though that there are no vulnerable structures or residential areas, people consider this areas to be at high risk, since during the 2011 flood, water entered the island through the canal above this area. It was mentioned that the canals in this area are highly polluted and there is a bad smell. Thus, in the case of flooding this polluted water would spread out and could cause health risks through contact with contaminated water. This suggests that the traditional approach to flood risk assessment has omitted an important factor.

The next step was to convert the raster representation of the traditional flood risk map into a polygon representation, as described in Sect. 3.3. Figure 15 shows the polygon representation of the traditional flood risk assessment following this conversion.

Visual inspection and a simple metric were adopted to assess the agreement between the two maps as described in Sect. 3.4. The agreement of these two maps was calculated as $48 \%$.

Next, we hypothesised that an area would be considered as being in a state of high risk if a certain fraction of the polygon was deemed in the traditional approach to be high risk. This was tested by designating a polygon as high risk if $10 \%$ of the cells were high risk. If not, the mean values from the risk values over the polygon were calculated. An improved agreement of $52 \%$ was found with this method. A second approach of selecting a $10 \%$ threshold with the modal value within each polygon selected otherwise. A reduced agreement of $40 \%$ was found. Next, the threshold value of $10 \%$ was varied, with values of 6 and $13 \%$ selected. Agreements of 36 and $44 \%$ were found. We decided that the $10 \%$ threshold was selected as an effective way to identify high risk cells, and calculating the 


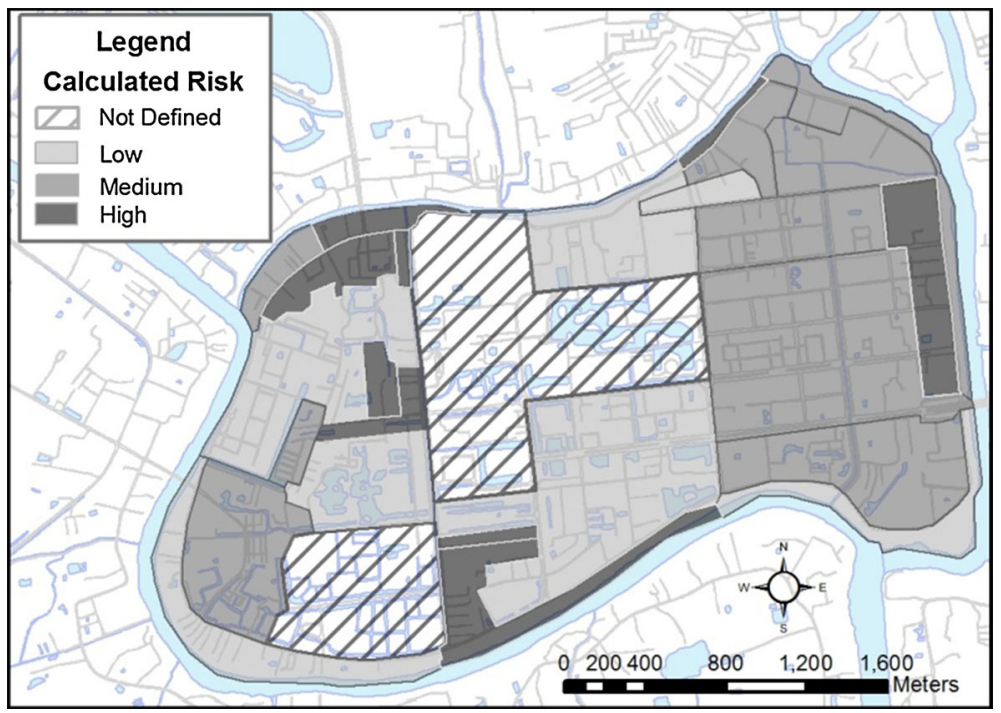

Fig. 15 Polygon representation of traditional (quantitative or analytical) flood risk map

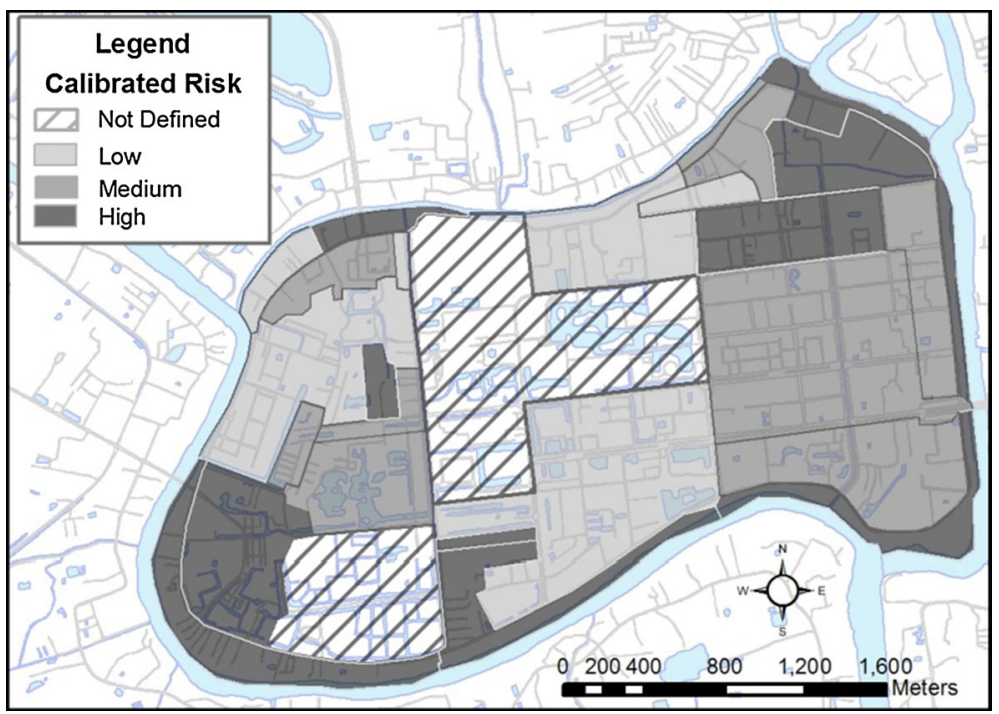

Fig. 16 Polygon representation of traditional (quantitative or analytical) flood risk map using $10 \%$ threshold (with mean of cell values otherwise)

mean value of the other cells within each polygon if this threshold was not exceeded. This adjusted flood risk map is shown in Fig. 16.

The next stage was to evaluate the agreement between the two maps by varying the weights of the four factors in the traditional flood risk map. Thirty scenarios, as described in Sect. 3.3, were evaluated. The results are shown in Table 6. 
Table 6 Agreement between risk perception and polygon representation of traditional flood risk map for 30 scenarios
Significant scenario results are highlighted

\begin{tabular}{|c|c|c|c|c|c|}
\hline Scenario & Economic & Social & Cultural & Physical & Agreement (\%) \\
\hline 1 & 0.25 & 0.25 & 0.25 & 0.25 & 52 \\
\hline 2 & 0.33 & 0.33 & 0.33 & 0 & 48 \\
\hline 3 & 0.33 & 0.33 & 0 & 0.33 & 36 \\
\hline 4 & 0.33 & 0 & 0.33 & 0.33 & 36 \\
\hline 5 & 0 & 0.33 & 0.33 & 0.33 & 40 \\
\hline 6 & 0.5 & 0.16 & 0.16 & 0.16 & 36 \\
\hline 7 & 0.16 & 0.5 & 0.16 & 0.16 & 44 \\
\hline 8 & 0.16 & 0.16 & 0.5 & 0.16 & 28 \\
\hline 9 & 0.16 & 0.16 & 0.16 & 0.5 & 28 \\
\hline 10 & 0.4 & 0.4 & 0.2 & 0.2 & 40 \\
\hline 11 & 0.4 & 0.2 & 0.4 & 0.2 & 36 \\
\hline 12 & 0.4 & 0.2 & 0.2 & 0.4 & 44 \\
\hline 13 & 0.2 & 0.4 & 0.4 & 0.2 & 52 \\
\hline 14 & 0.2 & 0.4 & 0.2 & 0.4 & 32 \\
\hline 15 & 0.2 & 0.2 & 0.4 & 0.4 & 32 \\
\hline 16 & 0.5 & 0.5 & 0 & 0 & 48 \\
\hline 17 & 0.5 & 0 & 0.5 & 0 & 32 \\
\hline 18 & 0.5 & 0 & 0 & 0.5 & 36 \\
\hline 19 & 0 & 0.5 & 0.5 & 0 & 44 \\
\hline 20 & 0 & 0.5 & 0 & 0.5 & 40 \\
\hline 21 & 0 & 0 & 0.5 & 0.5 & 36 \\
\hline 22 & 0.3 & 0.3 & 0.3 & 0.1 & 60 \\
\hline 23 & 0.3 & 0.3 & 0.1 & 0.3 & 36 \\
\hline 24 & 0.3 & 0.1 & 0.3 & 0.3 & 40 \\
\hline 25 & 0.1 & 0.3 & 0.3 & 0.3 & 32 \\
\hline 26 & 0.7 & 0.1 & 0.1 & 0.1 & 32 \\
\hline 27 & 0.1 & 0.7 & 0.1 & 0.1 & 44 \\
\hline 28 & 0.1 & 0.1 & 0.7 & 0.1 & 24 \\
\hline 29 & 0.1 & 0.1 & 0.1 & 0.7 & 28 \\
\hline 30 & 0.21 & 0.19 & 0.38 & 0.22 & 52 \\
\hline
\end{tabular}

During the adjustment process, several interesting points were observed, especially in Scenarios 26-29, where one factor was given a dominant weight (70 \%). When social and physical vulnerabilities dominate (see Fig. 17), most cells became high risk, whereas when cultural dominates, most cells become low risk (see Fig. 18). It is also interesting that good agreement was found using the weights from the consultation that were deemed too unreliable because of the small sample size (Scenario 30).

The best match between the traditional and perceived flood risk map was Scenario 22, where as well as selecting a threshold of $10 \%$, economic, social, and cultural vulnerabilities were given equal weights of $30 \%$ and the physical vulnerability was granted $10 \%$ weight. The total area of polygons where agreement was found was 492.4 ha. The residents assessed the risk to an area of 631.7 ha. The agreement of $60 \%$ of the polygons represents $77.9 \%$ of the assessed area. This flood map is shown in Fig. 19. 


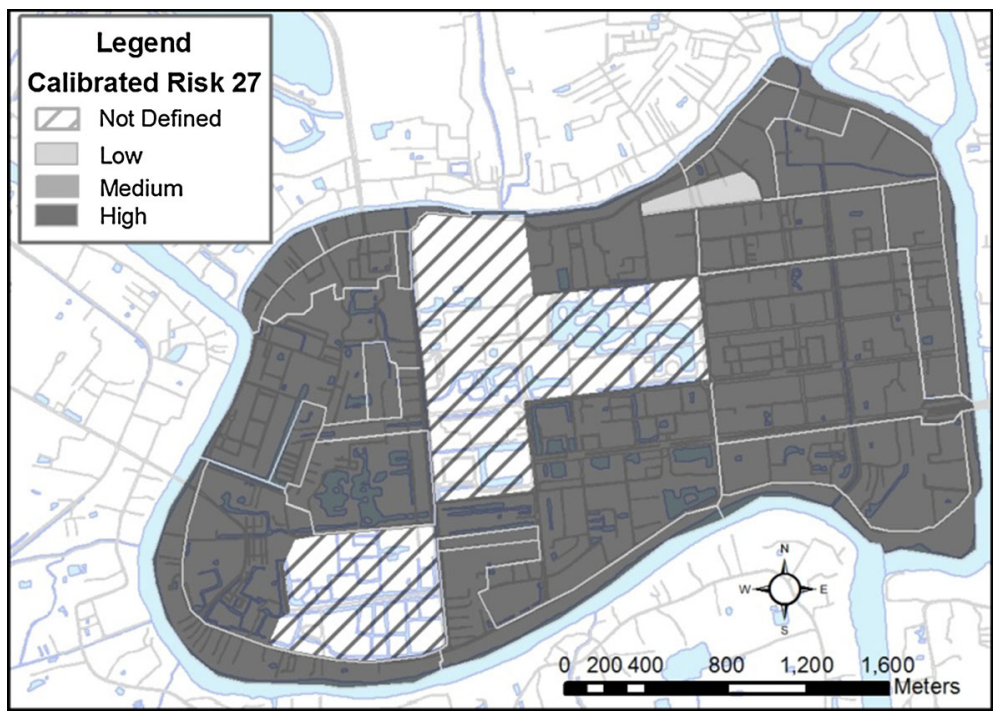

Fig. 17 High risk when social vulnerability dominates (Scenario 27)

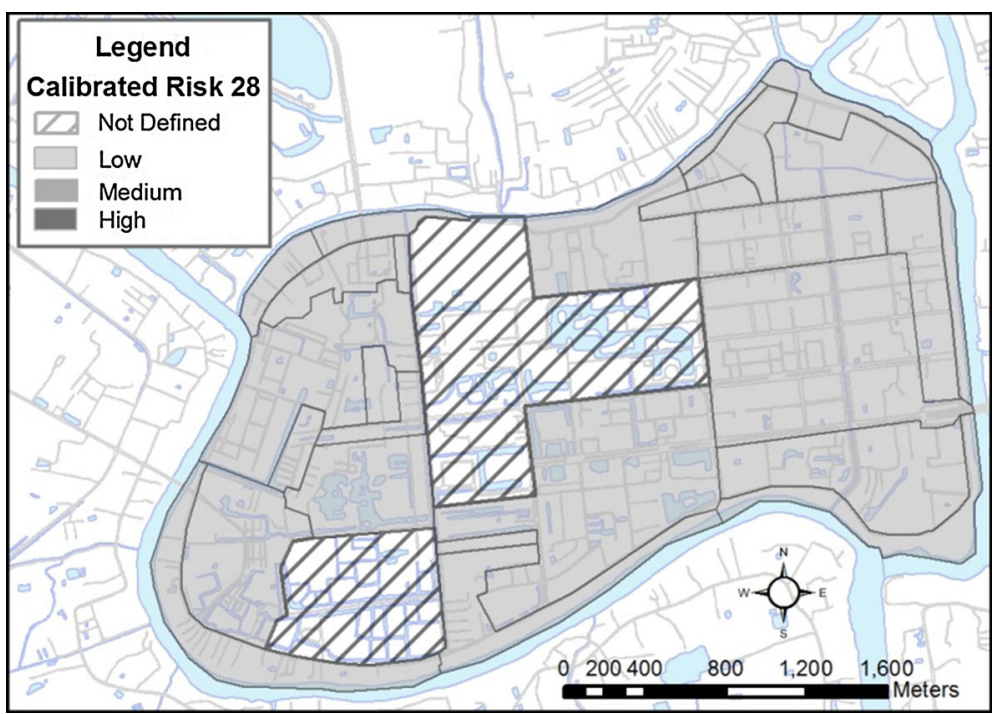

Fig. 18 Low risk when cultural vulnerability dominates (Scenario 28)

\section{Discussion and conclusions}

Two different approaches for flood risk assessment have been applied in the Ayutthaya case study, namely the traditional (quantitative or analytical) and risk perception (qualitative or perceptive) approaches. These approaches differ in many ways, including the definition of the term "risk", the characteristics of the disaster concerned, and the 


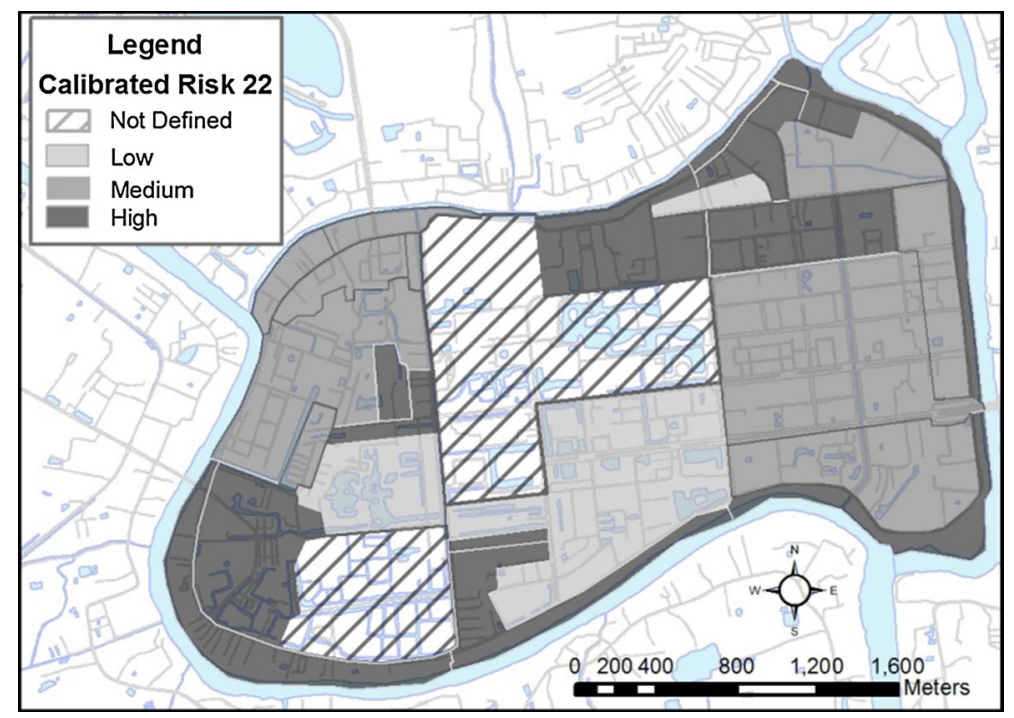

Fig. 19 Polygon representation of traditional flood risk map from Scenario 22 (best fit)

techniques for data analysis. Attempting to encounter risk from the holistic perspective, which is promoted throughout this paper, requires looking at risk from both approaches: the analytical approach (i.e. quantitative) and also the perceptive approach (i.e. intuitions, feelings and other forms of subjective experience).

The quantitative approach is dominated by analytical thinking (i.e. a form of thinking which is rooted in modern science) which attempts to calculate the phenomena with the intention of expressing it in a precise way.

The qualitative approach looks into phenomena from an intuitive perspective and the nature of the senses which we already carry in ourselves, but which can be further stimulated and enhanced by engaging in the process of seeing and experiencing the phenomenon with the sensuous-intuitive mind and with the sensorial-imaginative mind, and as such, it cannot be understood by the analytical and intellectual mind alone. It focuses on the root causes of flood risk related to human mental processes and the human scale. The present work demonstrates that flood risk is inherently a social process with social roots, and as such, it requires the holistic perspective which combines the two worlds. The differences in the derived flood risk maps demonstrate that two different approaches for flood risk assessment reveal different insights of the phenomena, and as such, they both should be used in the process of flood risk management.

Both approaches reveal valuable insights into the phenomena, and as such, they both should be used in the process of flood risk management. We argue in this paper that they are complementary, rather than oppositional, even if the results differ, and they should be used as such. As Slovic (1987) argued, risk managers should not discount the views of residents, but take their views into account.

The two approaches described here produce results that are not easily compatible, and the challenge of combining quantitative and qualitative data is not easy. In this study, the aim of the adjustment of one map by comparing it to the other is not intended to be a strictly mechanical rigorous process. Rather we have demonstrated an attempt to combine 
quantitative and qualitative data, and this process is explorative and relies on judgement and skill. In this study, we showed that the spatial resolutions of the two flood risk maps are very different. The traditional (quantitative or analytical) approach provides a raster flood risk map with a fixed cell size of a few metres, whereas people tend to assess risk on a large scale. This raises interesting questions over the best way to communicate flood risk. An over-reliance on the results of computational models may not be the most appropriate to relate to the spatial scale that people use to assess and communicate risk.

There are several benefits to the approach taken in this study. First, the traditional approach provides the possibility of testing potential flood risk reduction measures. It has been shown in some studies that the success of certain measure is at least partially dependent on the perception of risk, although this is still debated (Bubeck et al. 2012; Vojinovic and Abbott 2012; Grothmann and Reusswig 2006). Precautionary measures that rely on residents perceiving the risk will fail, if residents are unaware of the risk they face. Flood risk managers can identify areas of the highest risk based on the map derived with the traditional approach. However, both the legitimacy of flood risk reduction plan and risk behaviour of local residents rely heavily on the level of perceived risk.

The holistic risk assessment approach advocated in this study emphasises the need for a combination of quantitative and qualitative data and methods which can range from observations, measurements, model simulations, and economic analysis to signs, statements, experiences, feelings, and perceptions. It places a strong emphasis on social and ethical aspects and assessment of community's attitudes towards risk and risk-benefit trade-offs. It also applies social justice principles (e.g., maximising welfare, fairness, respecting individual rights and equality and promoting virtue) in combination with sharp analysis of social, ethical, and wider ecological considerations, while remaining technologically and economically efficient.

Acknowledgments This research was funded by the Asian Development Bank, under RETA 6498 Knowledge and Innovation Support for ADB's Water Financing Program (RETA 6498). This work was also partially funded by the European Union Seventh Framework Programme (FP7/2007-2013) under Grant agreement No 603663 for the research project PEARL (Preparing for Extreme And Rare events in coastaL regions). We would also like to thank the two anonymous reviewers for their valuable comments which helped improve the quality of this paper.

Open Access This article is distributed under the terms of the Creative Commons Attribution 4.0 International License (http://creativecommons.org/licenses/by/4.0/), which permits unrestricted use, distribution, and reproduction in any medium, provided you give appropriate credit to the original author(s) and the source, provide a link to the Creative Commons license, and indicate if changes were made.

\section{References}

Abbott MB, Vojinovic Z (2009) Applications of numerical modelling in hydroinformatics. J Hydroinform 11(3-4):308-319

Apel H, Aronica GT, Kreibich H, Thieken AH (2009) Flood risk analyses-how detailed do we need to be? Nat Hazards 49:79-98

Arnbjerg-Nielsen K, Willems P, Olsson J, Beecham S, Pathirana A, Bülow Gregersen I, Madsen H, Nguyen VTV (2013). Impacts of climate change on rainfall extremes and urban drainage systems: a review. Water Sci Technol 68(1):16-28

Birkholz S, Muro M, Jeffrey P, Smith HM (2014) Rethinking the relationship between flood risk perception and flood management. Sci Total Environ 478:12-20. doi:10.1016/j.scitotenv.2014.01.061

Birkmann J (2007) Risk and vulnerability indicators at different scales: applicability, usefulness and policy implications. Environ Hazards 7:20-31 
Bubeck P, Botzen WJW, Aerts J (2012) A review of risk perceptions and other factors that influence flood mitigation behavior. Risk Anal 32:1481-1495

Colette A (2007) Climate Change and World Heritage: report on predicting and managing the impacts of climate change on World Heritage and strategy to assist States Parties to implement appropriate management responses. In: Colette A (ed) World Heritage report, vol 22. UNESCO World Heritage Centre, Paris

Cunha LK, Krajewski WF, Mantilla R, Cunha L (2011) A framework for flood risk assessment under nonstationary conditions or in the absence of historical data. J Flood Risk Manag 4(1):3-22

Cutter SL, Mitchell JT, Scott MS (2000) Revealing the vulnerability of people and places: a case study of Georgetown County, South Carolina. Ann As Am Geogr 90(4):713-737

Daly C (2011) Climate change and the conservation of archaeological sites: a review of impacts theory. Conserv Manag Archaeol Sites 13(4):293-310

Damm M (2010) Mapping social-ecological vulnerability to flooding. PhD thesis. United Nations University, Bonn, Germany

Grothmann T, Reusswig F (2006). People at risk of flooding: why some residents take precautionary action while others do not. Nat Hazards 38(1-2):101-120

Gunderson LH (2000) Ecological resilience-in theory and in application. Annu Rev Ecol Systemat 31:425-439

Haase D (2011) Participatory modelling of vulnerability and adaptive capacity in flood risk management. Nat Hazards 67(1):77-97. doi:10.1007/s11069-010-9704-5

Hall JW, Dawson RJ, Sayers PB, Rosu C, Chatterton JB, Deakin R (2003) A methodology for national-scale flood risk assessment. Proc Inst Civ Eng-Water Marit Eng 156:235-247

Hammond MJ, Chen AS, Djordjevic S, Butler D, Mark O (2015) Urban flood impact assessment: a state-ofthe-art review. Urban Water J 12(1):14-29

Henonin J, Russo B, Mark O, Gourbesville P (2013) Real-time urban flood forecasting and modelling-a state of the art. J Hydroinform 15:717-736

Huong HTL, Pathirana A (2013) Urbanization and climate change impacts on future urban flooding in Can Tho city, Vietnam. Hydrol Earth Syst Sci 17:379-394. doi:10.5194/hess-17-379-2013

Intergovernmental Panel on Climate Change, I (2014) Summary for policy makers. In: Field CB, V.R. Barros, D.J. Dokken, K.J. Mach, M.D. Mastrandrea,, M. C. T.E. Bilir, K.L. Ebi, Y.O. Estrada, R.C. Genova, B. Girma, E.S. Kissel, A.N. Levy, S. MacCracken, \& a. L. L. W. e. P.R. Mastrandrea (Eds.), in Climate Change 2014: Impact, Adaptation, and Vulnerability. Part A: Global and Sectoral Aspects. Contribution of Working Group II to the Fifth Assessment Report of the Intergovernmental Panel on Climate Change (pp. 1-32). Cambridge, United Kingdom and New York, NY, USA

Jonkman SN, Vrijling JK, Vrouwenvelder ACWM (2008) Methods for the estimation of loss of life due to floods: a literature review and a proposal for a new method. Nat Hazards 46(1):353-389

Kahan DM (2012) Cultural cognition as a conception of the cultural theory of risk. In: Roeser S (ed) Handbook of risk theory. Springer, Berlin, pp 725-759

Kenyon W (2007) Evaluating flood risk management options in Scotland: a participant-led multi-criteria approach. Ecol Econ 64(1):70-81

Kincey M, Challis K, Howard AJ (2008) Modelling selected implications of potential future climate change on the archaeological resource of river catchments: an application of geographical information systems. Conserv Manag Archaeol Sites 10(2):113-131

Kubal C, Haase D, Meyer V, Scheuer S (2009) Integrated urban flood risk assessment-adapting a multicriteria approach to a city. Nat Hazards Earth Syst Sci 9:1881-1895

Kumar DS, Arya DS, Vojinovic Z (2013) Modeling of urban growth dynamics and its impact on surface runoff characteristics. Comput Environ Urban Syst 41:124-135

Marzeion B, Levermann A (2014) Loss of cultural world heritage and currently inhabited places to sea-level rise. Environ Res Lett 9:034001

Merz B, Hall J, Disse M, Schumann A (2010) Fluvial flood risk management in a changing world. Nat Hazards Earth Syst Sci 10:509-527

Messner F, Penning-Rowsell E, Green C, Meyer V, Tunstall S, Van der Veen A (2007) Evaluating flood damages: guidance and recommendations on principles and methods. FLOODSite Consortium, Wallingford, UK

Meyer V, Scheuer S, Haase D (2009) A multicriteria approach for flood risk mapping exemplified at the Mulde river, Germany. Nat Hazards 48(1):17-39

Mongkonkerd S, Hirunsalle S, Kanegae H, Denpaiboon C (2012) Comparison of direct monetary flood damages in 2011 to pillar house and non-pillar house in Ayutthaya, Thailand. Procedia Environ Sci 17:327-336 
Muller A, Reiter J, Weiland U (2011) Assessment of urban vulnerability towards floods using an indicatorbased approach—a case study for Santiago de Chile. Nat Hazards Earth Syst Sci 11:2107-2123

Mynett A, Vojinovic Z (2009) Hydroinformatics in multi-colours-part red: urban flood and disaster management. J Hydroinform 11(3-4):166-180

Pelling M (2011) Adaptation to climate change: from resilience to transformation. Routledge, London

Penning-Rowsell E, Floyd P, Ramsbottom D, Surendran S (2005) Estimating injury and loss of life in floods: a deterministic framework. Nat Hazards 36(1-2):43-64

Peters-Guarin G, McCall M, van Westen C (2012) Coping strategies and risk manageability: using participatory geographical information systems to represent local knowledge. Disasters 36(1):1-27. doi:10.1111/j.1467-7717.2011.01247.x

Price RK, Vojinovic Z (2008) Urban flood disaster management. Urban Water J 5(3):259-276

Price RK, Vojinovic Z (2011) Urban hydroinformatics: data, models, and decision support for integrated urban water management. IWA Publishing, London

Roachanakanan T (2013) Changing in drainage pattern and increasing flood risk in Thailand. Paper presented at the Asia Flood Conference, Bangkok, Thailand

Seyoum SD, Vojinovic Z, Price RK, Weesakul S (2012) A coupled 1d and non-inertia 2d flood inundation model for simulation of urban pluvial flooding. ASCE J Hydraulic Eng ASCE 138(1):23-34

Slovic P (1987) Perception of risk. Science 236(4699):280-285

Slovic P, Peters E (2006) Risk perception and affect. Curr Dir Psychol Sci 15:322-325

Ten Veldhuis JAE (2011) How the choice of flood damage metrics influences urban flood risk assessment. J Flood Risk Manag 4:281-287. doi:10.1111/j.1753-318X.2011.01112.x

Turner BL, Kasperson RE, Matson PA, McCarthy JJ, Corell RW, Christensen L, Schiller A et al (2003) A framework for vulnerability analysis in sustainability science. Proc Natl Acad Sci USA 100(14):8074-8079

Tversky A, Kahneman D (1974) Judgment under uncertainty: heuristics and biases. Science 185:1124-1131

UNISDR (2009) UNISDR terminology on disaster risk reduction. Geneva, Switzerland. Available at http:// www.unisdr.org/we/inform/publications/7817. Accessed 30 Nov 2015

Vecvagars K (2006) Valuing damage and losses in cultural assets after a disaster: concept paper and research options. United Nations, The World Bank and the Economic Commission for Latin America and the Caribbean, Mexico

Vojinovic Z (2014) Flood risk: the holistic perspective. From integrated to interactive planning for flood resilience. IWA Publishing, London

Vojinovic Z, Abbott MB (2012) Flood risk and social justice: from quantitative to qualitative flood risk assessment and mitigation. IWA Publishing, London

Vojinovic Z, Tutulic D (2009) On the use of 1D and coupled 1D-2D approaches for assessment of flood damages in urban areas. Urban Water J 6(3):183-199

Vojinovic Z, Seyoum SD, Mwalwaka JM, Price RK (2011) Effects of model schematization, geometry and parameter values on urban flood modelling. Water Sci Technol 63(3):462-467

Vojinovic Z, Seyoum S, Salum MH, Price RK, Fikri AF, Abebe Y (2012) Modelling floods in urban areas and representation of buildings with a method based on adjusted conveyance and storage characteristics. J Hydroinform 15(4):1150-1168

Wachinger G, Renn O, Begg C, Kuhlicke C (2013) The risk perception paradox-implications for governance and communication of natural hazards. Risk Anal 33:1049-1065

Wang JJ (2015) Flood risk maps to cultural heritage: measures and process. J Cult Herit 16(2):210-220

Wilhelmi OV, Morss RE (2013) Integrated analysis of societal vulnerability in an extreme precipitation event: a Fort Collins case study. Environ Sci Policy 26:49-62

Wisner B, Blaikie P, Cannon T, Davis I (2004) At risk: natural hazards, people's vulnerability, and disaster. Routledge, London 